\title{
Improving Productivity of Dairy Products by Effective Material Handling and Layout Design
}

\author{
Shubham Bhamare ${ }^{1}$ | Harshada Lambhate ${ }^{1} \mid$ B.R.Patil ${ }^{2}$ \\ 1UG Students, Dept. Mechanical Engineering, MIT Academy of Engineering, Alandi, Pune, Maharashtra, India \\ ${ }^{2}$ Assist. Professor, Dept. Mechanical Engineering, MIT Academy of Engineering, Alandi, Pune, Maharashtra, India
}

To Cite this Article

Shubham Bhamare, Harshada Lambhate, B.R.Patil , "Improving Productivity Of Dairy Products by Effective Material Handling and Layout Design", International Journal for Modern Trends in Science and Technology, Vol. 06, Issue 05, May 2020, pp.: 112-116; https://doi.org/10.46501/IJMTST060520

Article Info

Received on 04-April-2020, Revised on 29-April-2020, Accepted on 09-May-2020, Published on 15-May-2020.

\section{ABSTRACT}

To achieve the maximum productivity by optimum utilization of the available resources, effective planning and designing of manufacturing equipment and also manufacturing process is useful. Effective planning tends to minimum wastage of resources and thus helps in increasing productivity. The aim of this research paper is to study the design, plant and its management and implementation of industrial engineering equipment in a milk dairy industry. The study begins with observation of standard operation procedures the existing plant layout, the manufacturing equipment. We work on time study of few processes. We also find out the facts which will be helpful to increase the productivity. Time study, method study, layout study helps to reduce the superfluous movements of the workers.

KEYWORDS: Productivity, Fixture, Time study, Work study, Layout, etc.

Copyright (C) 2014-2020 International Journal for Modern Trends in Science and Technology

DOI: https://doi.org/10.46501/IJMTST060520

\section{INTRODUCTION}

There is huge demand of milk and milk products throughout the globe. About 225 to 394 grams / day milk or milk products is consumed per capita in India only. To fulfil the huge milk demand various institutions are come into existence. These are termed as Milk Dairy. Maharashtra state has huge number of such dairies. Some are private dairy, some are owned by state government, while some are cooperative societies. Each industry has their own design and own features. Some are more popular while some are not that much popular.

This popularity depends on quality, quantity and effectivity. These all three entities form integrated network which effects on productivity of dairy. In order to enhance these all three entities and thereby to increase the productivity, we researched the various aspects of the industry. Increasing industrial tools will help to enhance the production quantity effectively in less time with great product quality.

\subsection{OBJECTIVES}

- To work on time study of the procedures in order to have more production in less time

- To decrease the operational cost.

- Applying ergonomics for labor convenience.

- To find the effective plant layout or to improve the existing plant layout.

- To find the optimum manufacturing technique which leads to minimum wastage. 


\section{Methodology}

In order to have the comprehension of the production flow the knowledge of various activities that are being done in the dairy industry, we went through the facility and pointed out each small activity, from raw materials to finished product, involved in each product making process; the various storage places for various milk product, and noted how material flowed from one operation to other. A lot of techniques of industrial engineering that are effective to increase the productivity and tends to beneficial inminimizing the resource waste or power waste.

\section{A. Selection of Product}

There are various milk products are manufactured in dairy industry. Products like milk, yoghurt, cheese, paneer, flavored milk, ice cream, etc. products are manufactured in large quantity. Hence it was difficult to select one product for study purpose. As work study is affected by three considerations, viz. Human, technical, economic considerations. As all products that are manufactured in industry are the important; we decided to choose most demanded product i.e. milk manufacturing. So that it would be easier for us to collect the facts and record the data.

\section{B. Recording the facts}

As the whole procedure is rely on how accurately we recorded the facts, the data collection becomes the most crucial and quite time-consuming step. Primarily, we work on the time study, in order to have the detailed analysis of how the operation flow is going. We used stopwatch to measure the time taken by worker to complete his or her task. It was very difficult task to record the time by the means of stopwatch as it works on very minute level.

\section{b) Packing Process}

\begin{tabular}{|l|cr|}
\hline Sr. No. - Elements & Distance - Time $(\mathrm{s})$ & - \\
\hline 1 collects the packed bags in basket & 0 & 8 \\
\hline 2 take the basket a side & 0 & 1 \\
\hline 3 arrange the packets in neat order in basket & 0 & 20 \\
\hline 4 walk a distance to keep the basket outside & 12 & 30 \\
\hline 5 place the basket in a row & 0 & 3 \\
\hline 6 back to the packing $\mathrm{m} / \mathrm{c}$ & 12 & 25 \\
\hline
\end{tabular}

Figure: Packing Process Chart (b)

After classifying all elements properly as operation, transport, delay, storage and inspection; we prepared flow chart for these two processes:

\section{c) Process on Raw Milk}

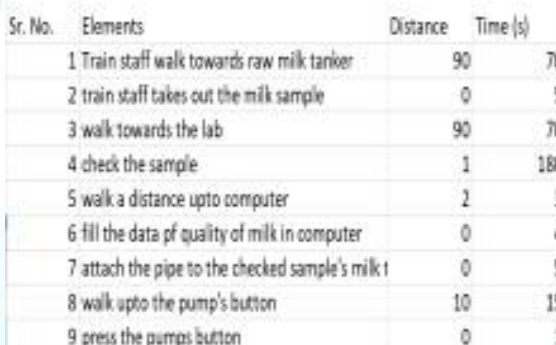

Figure: Flow Process Chart (c)

\section{d) Packing Process}

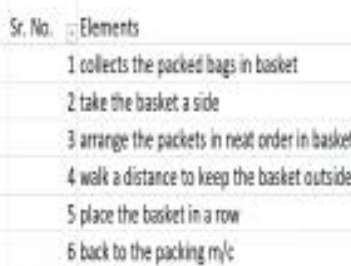

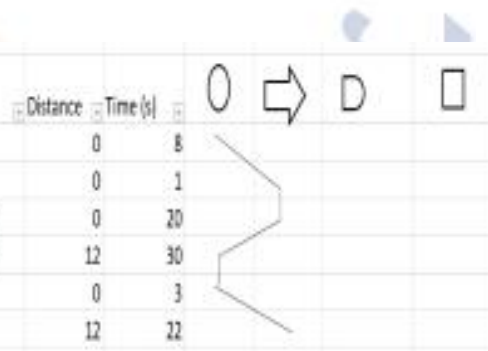

Figure: Flow Process Chart (d)
We had time study on mainly two process:

\section{a) Process of raw milk}

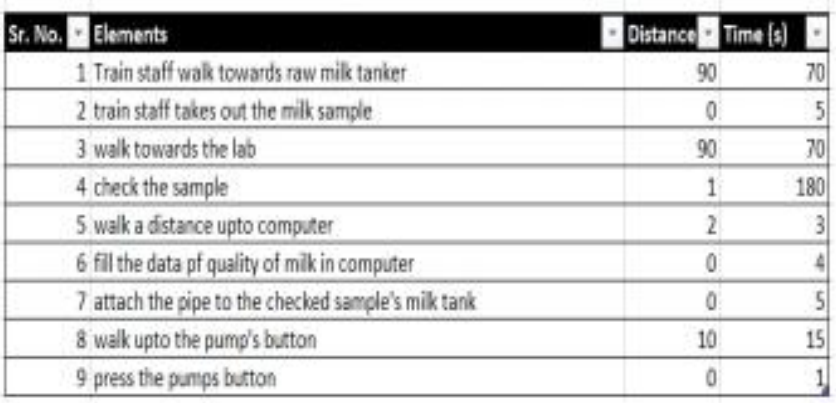

Figure: Raw MilkProcess chart (a)

\section{Types of Equipment's}

- $\quad$ Homogenizers

- Milk Pump

- Separators

- Mixing Pump

- Pasteurizers

- Milk Pouch Packing Machine

- Milk Tanks for storage

- Milk Weigh Bowl

- Hot Water Generator 


\section{Examining the Facts}

For the examination of facts, it consists of questioning rounds viz. primary and secondary questioning round. Questions asked on the basis of purpose, personnel, order i.e. sequence of activities: in order to suggest some changes in industry so as to reduce or eliminate the unnecessary activities and movement to achieve ultimate objective of increasing productivity by implementing industrial engineering management techniques.

\section{i. Problems Identifying}

- Inappropriate plant layout leads to unnecessary movements.

- Inappropriate placing of tools.

- Traditional material handling.

\section{ii. Developing the Improved Method}

Layout of an area is the arrangement of all machinery and materials. Flow analysis is done before proposing the changes in the plant layout, as changing plant layout is very expensive and time consuming process.

\section{iii. Existing Facility Layout}

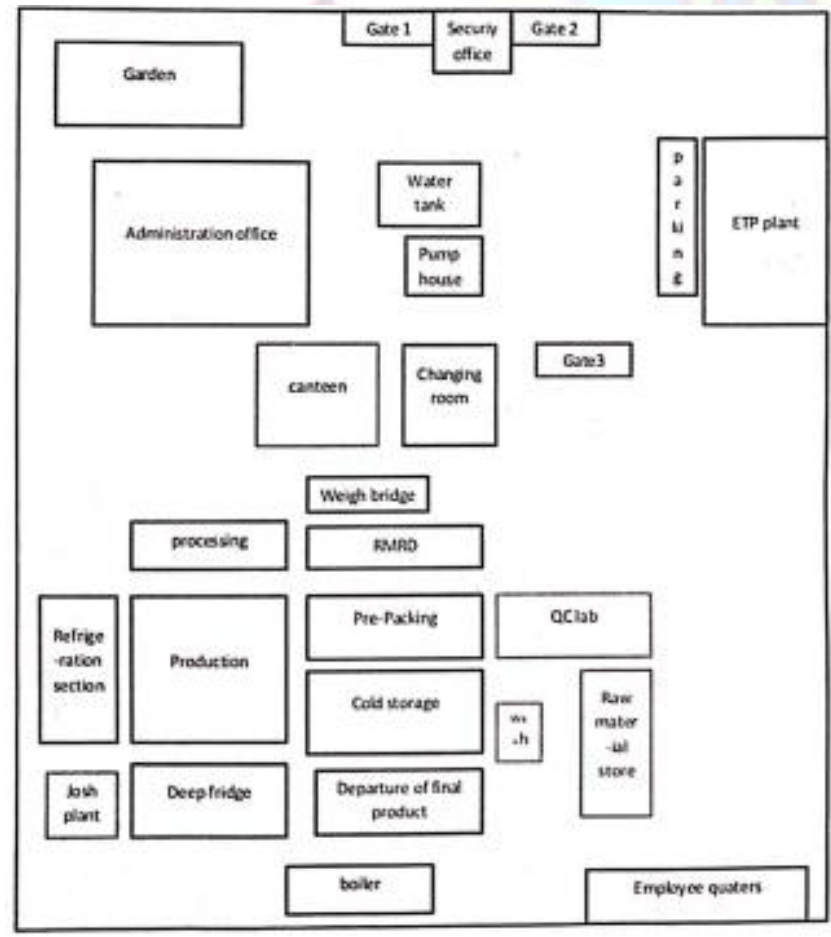

Figure: Existing layout

\section{iv. Proposed Layout}

The existing layout was occupying too much space and floor area which increases material handling time.To increase the productivity and decrease the time consumption, we have introduce a proposed layout which will help to reduce the material handling time and supply in the plant. To reduce the worker's fatigue, improve mobility of materials, ameliorate material accessibility, increase free space and improve worker and materials safety in accordance to convenience.

Material handling with safety of workers is very important so the changes had made to improve the safety and overall space for others utilization purpose. By changing the arrangement of sections and arranging it in flow of process so that the time required will be less and productivity will increase as per the flow increases.

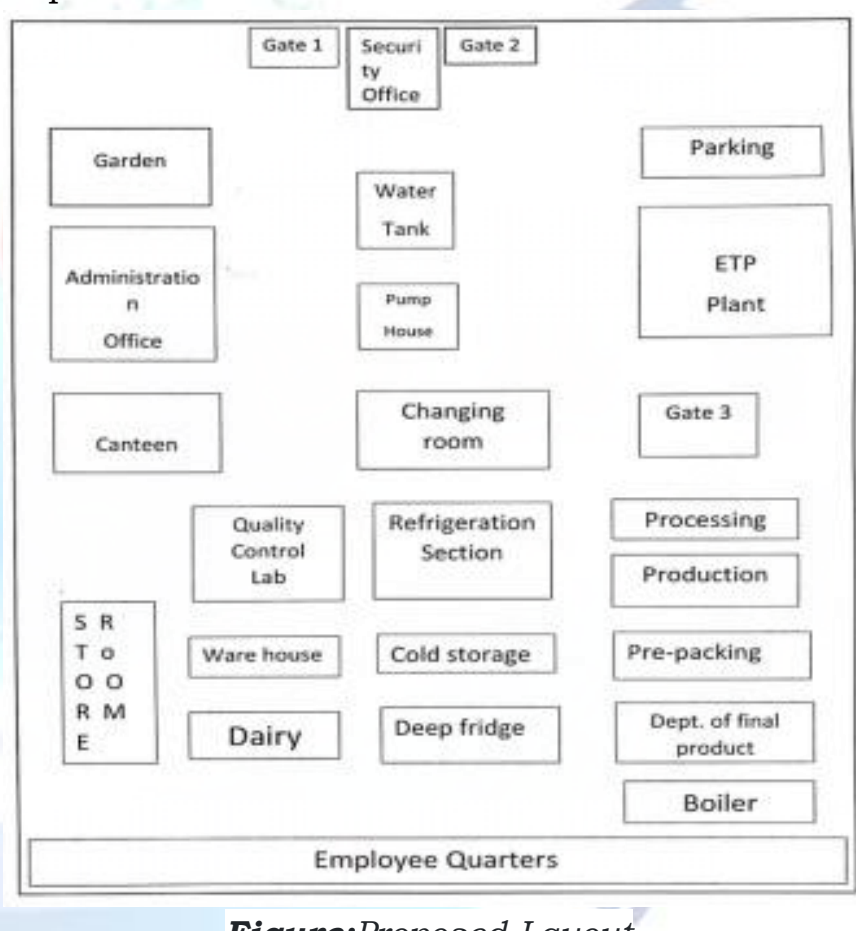

Figure:Proposed Layout

\section{v. Improvement in material Handling}

Material handling is the movement, protection, storage and control of materials and products throughout manufacturing, warehousing, distribution, consumption and disposal. Material handling and movement from one point to another point during processing, involves notable time and efforts. Inappropriate material handling leads to unnecessary Movements and also consumes more time. Although it is difficult to eliminate all such movements, as it become more expensive, but can improve these material handling by appropriate equipment and methods With regards to lowest cost and maximum safety. 
There are some equipment's which may reduce the waste of time and increase the overall productivity of the plant.

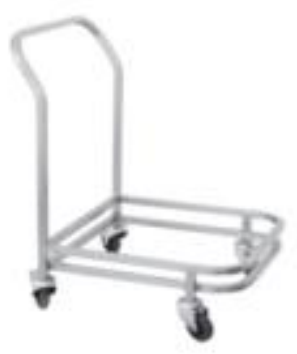

Figure: Platform trolley for movement of milkpackets

A no. of baskets of milk packets can put one by one on each other and can be delivered to storage where all baskets are placed. This reduces time which is involved in carrying one basket each at a time from packing machine to storage room

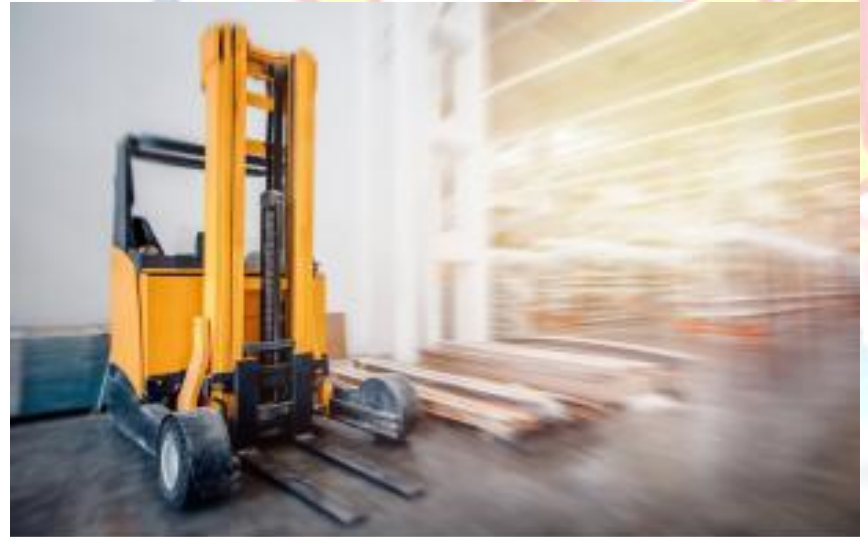

Figure: Forklifts are an essential piece of Material Handling Equipment

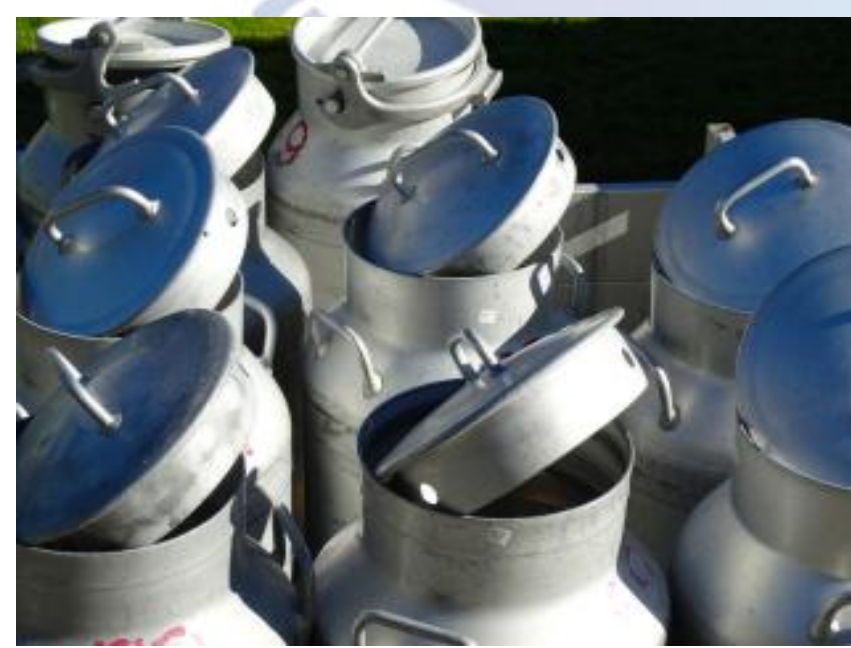

Figure: milk containers

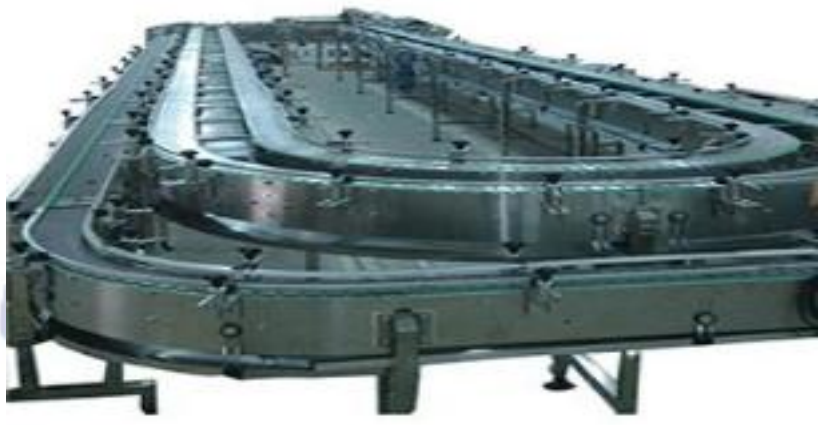

Figure: milk mobile belt conveyer

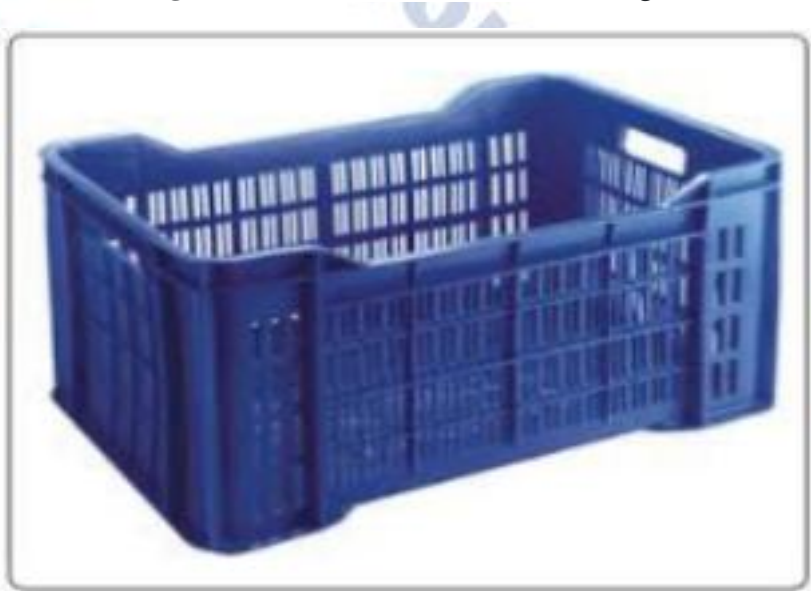

Figure: milk pouch carriage

- For Example :

\begin{tabular}{|c|c|c|}
\hline $\begin{array}{c}\text { Manufacturing } \\
\text { With: }\end{array}$ & $\begin{array}{c}\text { Present } \\
\text { Method }\end{array}$ & $\begin{array}{c}\text { Proposed } \\
\text { Method }\end{array}$ \\
\hline Batching Time & $40 \mathrm{~min}$ & $28.15 \mathrm{~min}$ \\
\hline Quality check & $25 \mathrm{~min}$ & $25 \mathrm{~min}$ \\
\hline Packaging Time & $60 \mathrm{~min}$ & $42 \mathrm{~min}$ \\
\hline Total Time (hours) & 2 hrs. 5 \\
min & 1 hrs. 35.15 \\
\hline min
\end{tabular}

Time Saved

$29.85 \mathrm{~min}$

Table: Observation

Therefore, total time saved in $1 \mathrm{batch}=29.85 \mathrm{~min}$

- Shift Timings 9:30am to 5:30am including lunch break of 30 minutes.

- Total Available time $=450$ minutes 
- Number of milk pouches produced and packed per Batch $=100$

- Number of working days in a month $=25$

\section{With Present Method}

Number of batches that can be performed is

$450 / 125=3.6$

Number of pouches that can be filled and packed in 3.6 batches is

$100 * 3.6=360$ pouches

Number of milk pouches that can be produced per Month is

$360 * 25=9000$ pouches

\section{With Proposed Method}

- Number of batches that can be performed

$$
450 / 95.15=4.72 \text { batches }
$$

- Number of milk pouches that can be produced And packed in 4.8 batches

$$
4.7 * 100=470 \text { pouches }
$$

- Number of milk pouches that can be produced per monthis

$$
470 * 25=11,750 \text { pouches }
$$

- Increment in production and packing of milk pouches is

$$
11,750-9000=2,750 \text { pouches }
$$

Therefore, increment in productivity is

$$
2,750 / 9000 * 100=30.55 \%
$$

\section{REFERENCES}

[1] J. Tompkins, J. White, Y. Bozer, J. Tanchoco, Facilities Planning 3rd Edition. John Wiley \& Sons, New Jersey

[2] Effective Management of Long-Term Care Facilities 3rd Edition

[3] http://www.researchdirections.org/Management/articleu pload/S6wLI6Qewb.pdf

[4] Manufacturing Facilities Design and Material Handling" by Fred E Meyers and Matthew P Stephens

[5] "Plant Layout and Facility Planning" by Jack Greene

[6] "Plant Design, Facility Layout, Floor Planning" by Jack Greene

\section{Conclusion}

This above study analysed the existing way of milk processes and layout. Which has i increased the productivity and decrease the human efforts of material handling by implementation of proposed layout and material handling methods.

With the implementation of work study principles, the results of the study were a success. Production operators were instrumental to the success of each improved methods. 